\title{
Gravity Anomalies and Flexure of the Lithosphere: A Three-Dimensional Study of the Great Meteor Seamount, Northeast Atlantic
}

\author{
A. B. WatTs \\ Lamont-Doherty Geological Observatory, Palisades, New York 10964
}

\section{J. R. Cochran}

Lamont-Doherty Geological Observatory, Palisades, New York 10964 Department of Geological Sciences, Columbia University, New York, New York

\author{
10027
}

\section{G. SELZER}

Lamont-Doherty Geological Observatory, Palisades, New York 10964

\begin{abstract}
Simple models for the flexure of the lithosphere caused by the load of the Great Meteor seamount have been determined for different assumed values of the effective flexural rigidity of the lithosphere. The models utilize a new method for determining the flexure of the lithosphere caused by a three-dimensional load. The gravity effect of the models has been computed and compared with observed free-air anomalies in the vicinity of the seamount. Computations show that the observed free-air anomalies can be most satisfactorily explained for an assumed effective flexural rigidity of the lithosphere of about $6 \times 10^{28}$ dyn $\mathrm{cm}$. This value, which is similar to other values determined for loads of different ages, suggests that the oceanic lithosphere is rigid enough to support applied loads for periods of time of at least several tens of millions of years.
\end{abstract}

\begin{abstract}
A basic postulate of the modern concept of plate tectonics is that a strong rigid outer layer of the earth (the lithosphere) overlies a weaker layer (the asthenosphere). The assumption that lithospheric plates act as rigid units for up to a few hundreds of millions of years is implicit in the reconstruction of past plate motions. It may seem at first that the concept of rigid lithospheric plates is contrary to the principle of isostasy, which in the classical formulation by Airy implies that flow may occur at shallow depths in the crust in response to applied stress differences. However, a number of early studies [Barrell, 1915; Gunn, 1943, 1947, 1949; Vening Meinesz, 1931; Heiskanen and Vening Meinesz, 1958] emphasized the importance of considering the finite strength of the outer layer of the earth in explaining a variety of geological and geophysical data in the vicinity of surface loads. The concept of regional compensation introduced by Vening Meinesz [1931] provides a method by which topography can be supported that is consistent with the existence of a strong lithosphere. In particular, Vening Meinesz [1941] found that gravity anomalies near Hawaii could be best explained if the lithosphere responded to applied surface loads in the same manner as if it were a uniform elastic beam overlying a weak fluid.

The concept of plate tectonics has increased interest in the long-term mechanical behavior of the lithosphere. Walcott has studied applied loads of long duration associated with sediments [Walcott, 1972], the interior plains of Canada [Walcott, 1970b], and the Hawaiian ridge [Walcott, 1970c]. Walcott [1970a] concluded that the lithosphere responds to long-term loads as a viscoelastic substance with a time constant of about $10^{6}$ years. This model implies that although the lithosphere will support applied loads, its rigidity decreases with time, and therefore compensation of the load becomes more and more local in nature.
\end{abstract}

Copyright $\odot 1975$ by the American Geophysical Union.
Recent studies have used gravity anomalies to examine the manner in which the lithosphere responds to surface loads [Cochran, 1973; Watts and Talwani, 1974; Watts and Cochran, 1974]. The mass distribution implied in the manner in which the lithosphere supports surface loads generally gives rise to characteristic anomalies that can easily be distinguished in observed free-air anomalies. From a study of the flexure of the lithosphere caused by the Hawaiian-Emperor seamount chain Watts and Cochran [1974] concluded that the lithosphere has a finite strength and that no difference can be discerned in the effective flexural rigidity deduced from loads of greatly different ages. This model implies that the effective flexural rigidity of the lithosphere reaches a finite, nearly constant value after a few million years of loading and that it is rigid enough to support surface loads for periods of time of at least several tens of millions of years.

The most useful parameter in loading studies is the effective flexural rigidity, which is a measure of the resistance of the lithosphere to deformation. A 'best-fitting' effective flexural rigidity that most completely explains geological and geophysical data in the vicinity of the load is usually determined. It should be noted that the effective flexural rigidity is not the actual rigidity of the lithosphere but is rather the rigidity of a uniform elastic beam that responds to an applied load in the same manner as the lithosphere would. The success of the simple model of flexure in explaining a wide variety of geological and geophysical data associated with surface loads is, however, strong support for the assumption that the effective flexural rigidity is closely related to the actual properties of the lithosphere.

The studies mentioned above involved almost exclusively two-dimensional models and thus were confined to features that could be approximated as being two dimensional, such as continental margins and volcanic ridges. Walcott $[1970 \mathrm{c}]$ used a three-dimensional model to study the deflection near the end 
of the Hawaiian ridge. Although he did not detail his method, he apparently found the average load in an annulus surrounding the deflection point and used an expression for a ring load.

In this paper we present a method for determining the flexure of the lithosphere caused by a three-dimensional surface load and apply the method to determine the flexure of the lithosphere caused by the Great Meteor seamount in the northeast Atlantic. In addition, we use observed free-air gravity anomalies in the vicinity of the seamount to deduce a bestfitting effective flexural rigidity for the oceanic lithosphere in that region. We then discuss the significance of this value in relation to the long-term mechanical properties of the lithosphere and to regional changes in its thickness.

\section{THEORY OF METHOD}

The deflection of a uniform elastic beam (or plate) overlying a fluid substratum caused by a three-dimensional load was first considered by Hertz [1884], who took as his physical example a load applied to a sheet of ice. He solved the basic differential equation

$$
D \cdot \nabla^{4} z+\left(\rho_{m}-\rho_{c}\right) g z=P
$$

for the case where $P$ is a point load applied at the origin. In (1), $g$ is gravity; $\rho_{m}$ and $\rho_{c}$ are the densities of the material beneath and above the plate, respectively; and $D$ is the flexural rigidity of the plate. The coordinate system is chosen with the $z$ axis positive in the upward direction. Hertz obtained as the solution for the deflection $z$,

$$
z=\frac{a^{2} P}{2 \pi\left(\rho_{m}-\rho_{c}\right) g} \int_{1}^{\infty} \frac{e^{-a r v} \sin (a r v) d v}{\left(v^{2}-1\right)^{1 / 2}}
$$

where $r$ is the distance from the point where the load is applied to the point where the deflection is measured, $v$ is an integration variable, and $a^{4}=\left(\rho_{m}-\rho_{c}\right) g / 4 D ; a$ has dimensions of reciprocal distance and was referred to as the "lithospheric constant' by Gunn [1943]. Walcott $[1970 a, b, c]$ defined $1 / a$ as the 'flexural parameter.'

Equation (2) may be expanded around the origin first as a series of Bessel functions, then in powers of $r$ [Hertz, 1884] to obtain

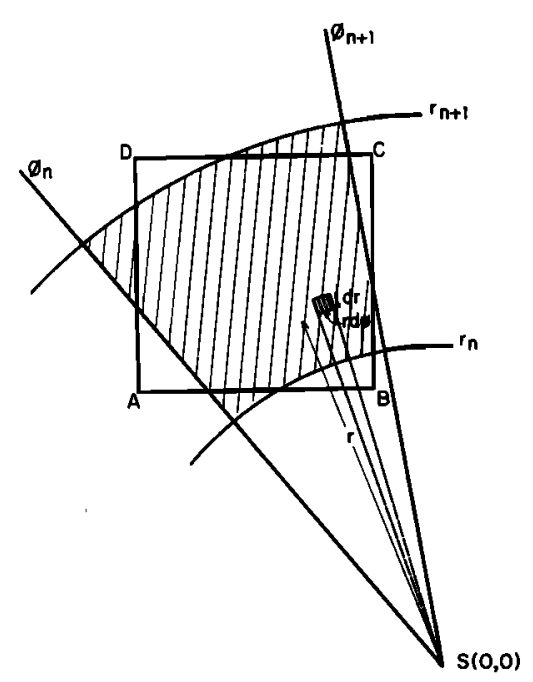

Fig. 1. Schematic representation of a three-dimensional load as a differential sector of two circles; $S$ is the point at which the deflection is computed, and $r d \phi d r$ is an area element.

$$
\begin{aligned}
z= & \frac{a^{2} P}{2 \pi\left(\rho_{m}-\rho_{c}\right) g}\left\{\frac{a^{2} r^{2}}{2^{2}} \log (a r)\right. \\
& -\frac{a^{6} r^{6}}{2^{2} \cdot 4^{2} \cdot 6^{2}}\left(\log (a r)-\frac{5}{6}+\cdots\right) \\
& +\frac{\pi}{4}\left(1-\frac{a^{4} r^{4}}{2^{2} \cdot 4^{2}}+\frac{a^{8} r^{8}}{2^{2} \cdot 4^{2}+6^{2} \cdot 8^{2}}-\cdots\right) \\
& \left.-(1+\log 2-C)\left(\frac{a^{2} r^{2}}{2^{2}}-\frac{a^{6} r^{6}}{2^{2} \cdot 4^{2} \cdot 6^{2}}+\cdots\right)\right\}
\end{aligned}
$$

where $C$ is a constant with the value 0.57721 . Equation (3) is a good approximation to (2) and is well behaved in the range in which it is applied in this study $(a r<1)$.

Equation (3) is in a form appropriate to be integrated over the load to obtain the deflection due to a distributed load. For purposes of computation the load is most conveniently treated as a rectangular array of, for example, the average elevation above an assumed base line of $10 \times 10 \mathrm{~min}$ squares. Equation (3) can then be integrated over each square and summed for all the squares composing the load to obtain the total deflection. The function to be integrated, however, is expressed in terms of the distance from the point at which the deflection is to be computed to the load element and is thus more easily integrated in polar rather than rectangular coordinates. The load could be expressed in compartments that are symmetrical about the point at which deflection is to be calculated, as is done in the computation of gravity terrain corrections. However, this involves the tedious procedure of computing a new set of load divisions for each deflection point.

We choose, rather, to work with rectangular divisions and to approximate each as the differential sector of two circles (Figure 1). We take $r_{n+1}-r_{n}=s$ and $\Delta \phi=\phi_{n+1}-\phi_{n}=s / p$, where $s$ is the length of a side of the load division and $p$ is the distance from the center of the load division to the deflection. This is a good approximation if $s \ll p$. If the load division is close to the deflection point, the division is subdivided so that this condition holds. If the deflection point is within the load division or at a great distance from it, the load division is treated as a point load.

From Figure 1 an area element is given by $r d r d \phi$. Integration over $r$ gives

$$
\begin{aligned}
z= & \frac{a^{2} P \Delta \phi}{2 \pi\left(\rho_{m}-\rho_{c}\right) g}\left[\frac{a^{2} r^{4}}{4}\left(\frac{\log (a r)}{4}-\frac{1}{16}\right)\right. \\
& -\frac{a^{6} r^{8}}{2^{2} \cdot 4^{2} \cdot 6^{2}}\left(\frac{\log (a r)}{8}-\frac{1}{64}-\frac{5}{6} \cdot \frac{1}{8}\right) \\
& +\frac{\pi}{4}\left(\frac{r^{2}}{2}-\frac{1}{6} \cdot \frac{a^{4} r^{6}}{2^{2} \cdot 4^{2}}+\frac{1}{10} \cdot \frac{a^{8} r^{10}}{2^{2} \cdot 4^{2} \cdot 6^{2} \cdot 8^{2}}\right) \\
& \left.-(1-\log 2-C)\left(\frac{a^{2} r^{4}}{16}-\frac{1}{8} \cdot \frac{a^{6} r^{8}}{2^{2} \cdot 4^{2} \cdot 6^{2}}\right)\right]
\end{aligned}
$$

which is evaluated between the limits $r=p+(s / 2)$ and $r=p-$ $(s / 2)$ to give the contribution from the load division.

We show in Figure 2 a comparison between the deflections obtained from a two-dimensional calculation and those obtained from three-dimensional calculations due to different types of loads. In each case the load had a cross section consisting of a block $5 \mathrm{~km}$ high and $112 \mathrm{~km}$ wide. The deflections have been computed for an assumed effective flexural rigidity of $1 \times 10^{30}$ dyn $\mathrm{cm}$. In the 'square' load the deflection curve is 

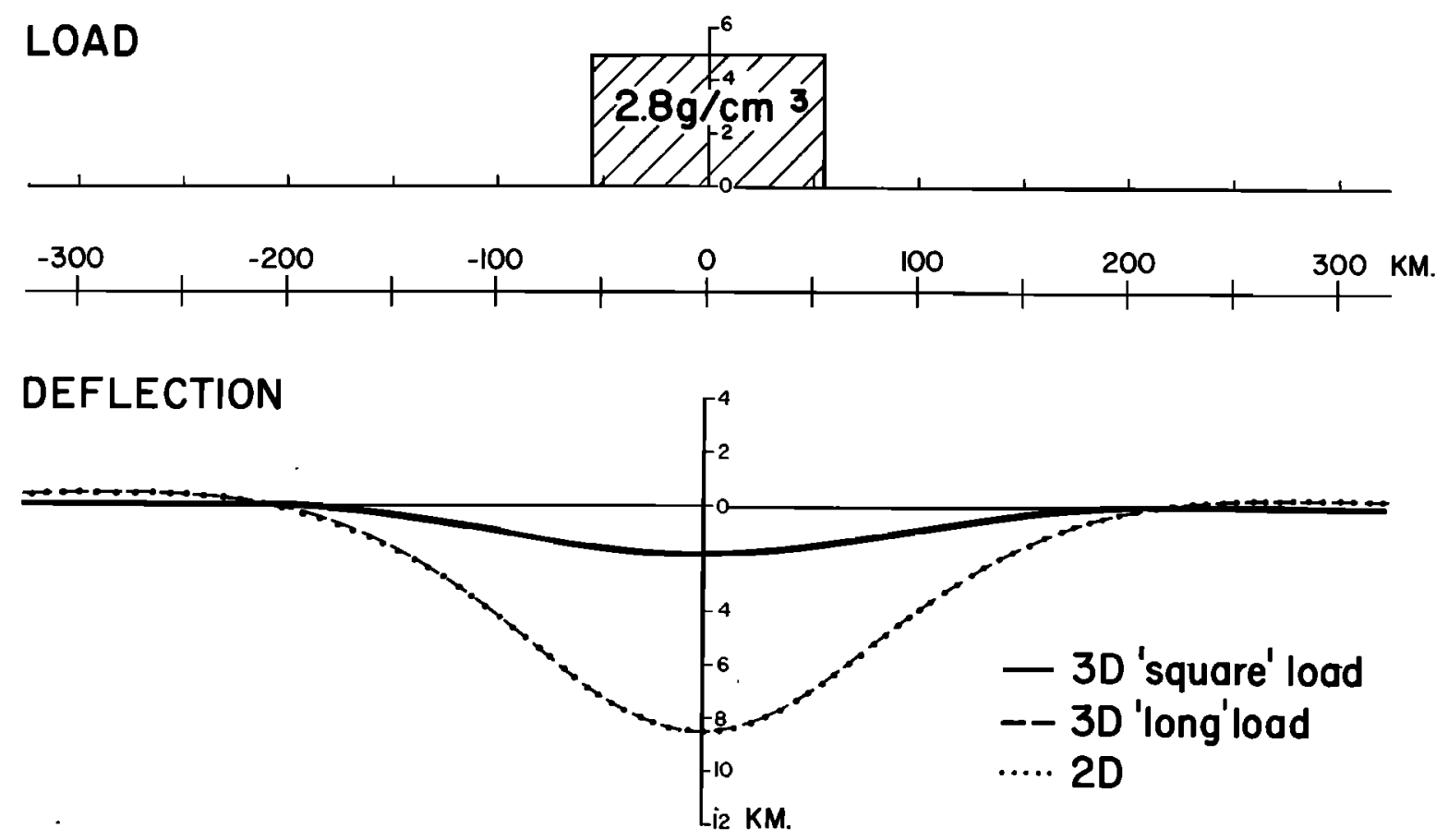

Fig. 2. Comparison of the deflection of an elastic beam (or plate) caused by two-dimensional and three-dimensional surface loads. The effective flexural rigidity of the beam is assumed to be $1 \times 10^{80} \mathrm{dyn} \mathrm{cm}$. Note that the deflection of the beam is similar for the case of a two-dimensional load (2D) and a three-dimensional load that extends several hundreds of kilometers normal to the profile (3D 'long' load). For a load as long as it is wide (3D 'square' load) the deflection is about a factor of 4 less than it is for a two-dimensional load.

for a profile through the center of a load extending $112 \mathrm{~km}$ normal to the profile. The maximum deflection was slightly under $2 \mathrm{~km}$. The 'long' load case is a profile across the center of a $1200-\mathrm{km}$-long load. This is a situation where a twodimensional model should be applicable, and indeed, the two curves agree closely, the maximum difference being only a few tens of meters. The large difference in the deflection between the square load and the long load cases illustrates the necessity of using a three-dimensional approach in considering loads of the size of individual seamounts.

\section{Application of Method to the Great Meteor Seamount}

Great Meteor seamount, discovered during the 1937 cruise of the F/S Meteor, is a broad flat-topped seamount located at $30^{\circ} \mathrm{N}, 28^{\circ} 30^{\prime} \mathrm{W}, 1280 \mathrm{~km}$ west of Africa and $720 \mathrm{~km}$ south of the Azores (Figure 3). The seamount forms part of a chain of seamounts trending south from the Azores, which also includes the Atlantis, Cruiser, and Hyeres seamounts.

The bathymetry of the seamount has been discussed by Heezen et al. [1954], Pratt [1963], and Heezen and Hollister [1971]. We present in Figure 3 a bathymetry map of the seamount that was compiled from charts of Pratt [1963] and Uchupi [1971] and data gathered during the 1965 cruise of the F/S Meteor [Fleischer et al., 1970] and the 1966 cruise of the $\mathrm{R} / \mathrm{V}$ Vema. The seamount has a broad summit at a depth of about $250 \mathrm{~m}$ elongate in a north-south direction and an elliptical base at a depth of about $4400-4800 \mathrm{~m}$. The upper slopes of the seamount dip steeply (up to about $12^{\circ}$ ) to a depth of about $2200 \mathrm{~m}$. At greater depths the slope decreases to form a broad apron surrounding the base of the seamount.

Although a number of dredge hauls have been carried out on the summit and slopes of the seamount, its age is not known with certainty. Pratt [1963] has described foraminiferal limestones from the summit of the seamount that are unlikely to be younger than Miocene in age. Heezen and Hollister [1971] have described reef rocks from the summit and lavas from the slopes, but these rocks have not been dated.

Seismic reflection and refraction studies of the seamount have been discussed by Hinz [1969] and Aric et al. [1970]. The uppermost part of the seamount consists of sediments with velocities of $2.7-3.8 \mathrm{~km} / \mathrm{s}$. The sediments are underlain by 'basement' rocks with velocities of $5.9-6.0 \mathrm{~km} / \mathrm{s}$. The deep crustal structure beneath the seamount is uncertain, and the depth to the 'Moho' has not been determined.

Gravity measurements in the vicinity of the Great Meteor seamount were obtained during the 1965 cruise of the F/S Meteor [Fleischer et al., 1970] and the 1966 cruise of the R/V Vema (Figure 3). The measurements during both cruises were obtained with the improved versions of the Graf-Askania sea gravimeter described by Graf and Schulze [1961] mounted on gyrostabilized platforms. The platform used during the $F / S$ Meteor cruise was an Anschütz platform [Fleischer et al., 1970], and that used during the R/V Vema cruise was an Alidade platform. The platforms differ mainly in the type of primary vertical reference and erection networks used to slave them.

In addition to errors in the measuring instruments, errors arise in gravity measurements owing to horizontal and vertical accelerations acting on the ship. In Graf-Askania sea gravimeters mounted on gyrostabilized platforms the most significant of these are the cross-coupling and off-leveling errors [LaCoste and Harrison, 1961]. The cross-coupling error was minimized during the F/S Meteor cruise by adding the uncorrected gravity signal from two oppositely mounted gravimeters. During the cruise of the $\mathrm{R} / \mathrm{V}$ Vema a single gravimeter was used. The cross coupling was computed in real time and subtracted from the uncorrected gravity signal. 


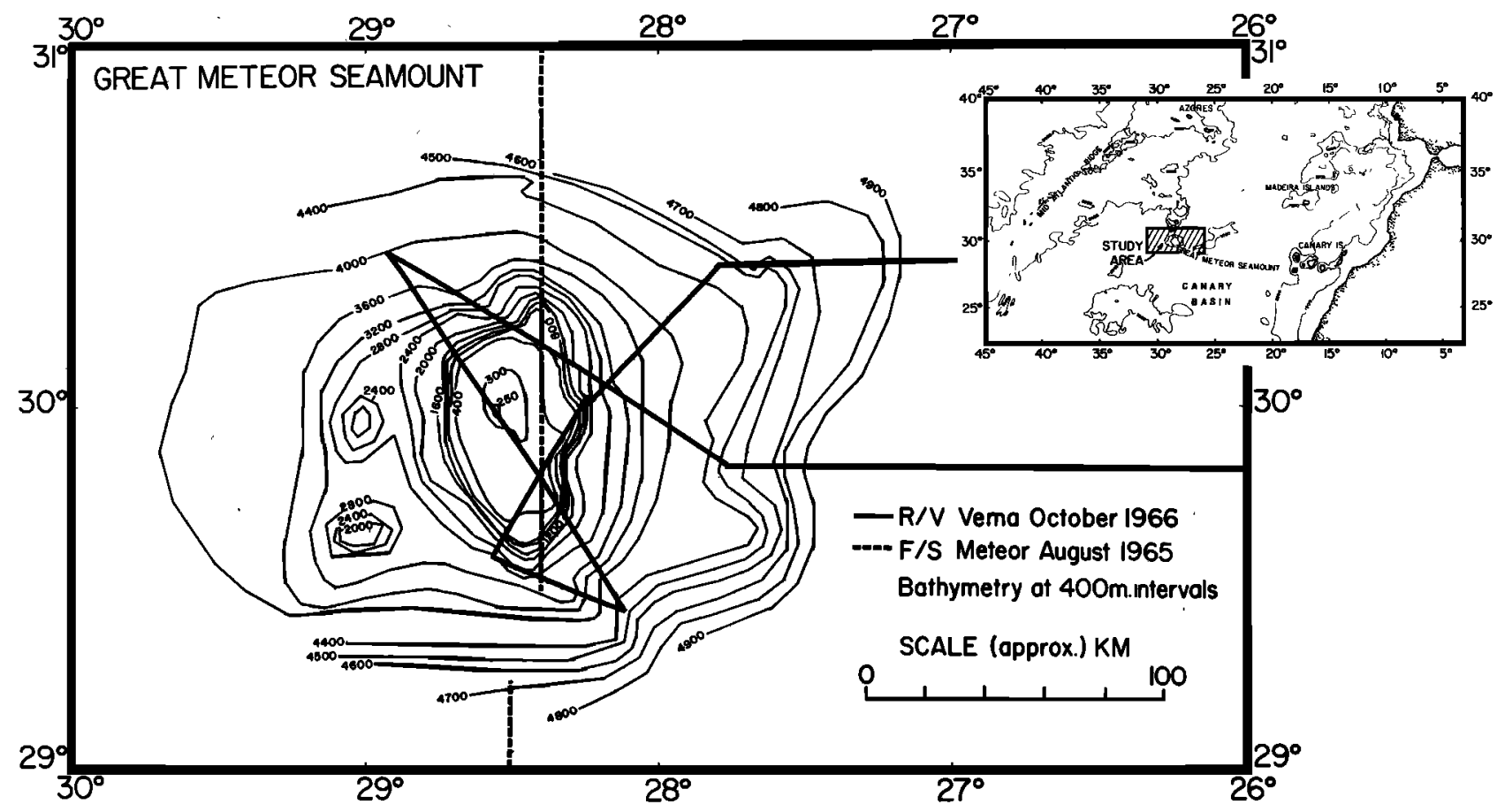

Fig. 3. Ship's tracks of the R/V Vema and the F/S Meteor in the region of the Great Meteor seamount. The bathymetry of the seamount has been compiled from work of Pratt [1963] and Uchupi [1971] and data obtained on the R/V Vema and $\mathrm{F} / \mathrm{S}$ Meteor cruises.

The overall accuracy of the gravity measurements has been estimated from an analysis of discrepancies at intersecting ship's tracks. An analysis of intersections shows that signifcant differences occur between the cruises of the F/S Meteor and those of the R/V Vema. The largest discrepancies occur in regions of steep gravity gradients and could be explained in part by uncertainties in navigation. In these regions we have relied on the $\mathrm{R} / \mathrm{V}$ Vema data, since the $\mathrm{R} / \mathrm{V}$ Vema was equipped with a satellite navigation system. We were able to analyze intersections of the $\mathrm{R} / \mathrm{V}$ Vema cruise with more recent cruises of the R/V Vema in the area. The overall accuracy of the 1966 survey estimated from the mean discrepancy of 11 of these intersections is $6.0 \mathrm{mGal}$.

The deflection of the lithosphere caused by the load of the Great Meteor seamount has been computed by using the method for three-dimensional loads outlined in the previous section. The load was obtained from the bathymetry map in Figure 3 by averaging the elevation above a 'base line' over 10 $\times 10 \mathrm{~min}$ squares. The base line was determined from the regional topography in the region of the seamount and slopes $\mathrm{E} 21^{\circ} \mathrm{S}$ from a depth of about $4400 \mathrm{~m}$ on the western side of the seamount to about $4900 \mathrm{~m}$ on the eastern side.

The densities required in the computations are the density of the load, the density of the material infilling the deflection, and the density of the substratum. The choice of suitable values for these parameters at seamounts has been discussed by Watts and Cochran [1974]. In this study we assume that the density of the load is $2.8 \mathrm{~g} / \mathrm{cm}^{3}$, the density of the material infilling the deflection is $2.8 \mathrm{~g} / \mathrm{cm}^{3}$, and the density of the substratum is 3.4 $\mathrm{g} / \mathrm{cm}^{\mathrm{s}}$.

We show in Figure 4 the computed deflection of the lithosphere due to the load of the Great Meteor seamount for an assumed effective flexural rigidity of the lithosphere, $D$, of 6 $\times 10^{29} \mathrm{dyn} \mathrm{cm}$. The main feature of the deflection is a nearly circular depression that extends beneath the load and some distance beyond it (Figure 4). The maximum depression occurs beneath the crest of the seamount and is about $2.6 \mathrm{~km}$. In addition, a broad region of slight uplift borders the circular depression. The distance to the region of uplift is $220 \mathrm{~km}$, and the maximum uplift is about $30 \mathrm{~m}$.

We have calculated the gravity effect of the simple flexure models using the three-dimensional method of Talwani and Ewing [1960]. The gravity effect of the flexure models is simply the sum of the gravity effect of the deflection and the gravity effect of the load. The density contrast associated with the deflection is assumed to arise at the layer 2-layer 3 boundary and at the Moho. Uniform density contrasts of -0.1 and -0.4 $\mathrm{g} / \mathrm{cm}^{3}$, respectively, were assumed at these boundaries. In the computations we assume a thickness of $1.5 \mathrm{~km}$ for layer 2 and $5.0 \mathrm{~km}$ for layer 3 . These thicknesses are in general agreement with the seismic structure of the oceanic crust deduced in other regions of the Atlantic [Ewing, 1969]. Since the load displaces water, a uniform density contrast of $(2.80-1.03)=1.77$ $\mathrm{g} / \mathrm{cm}^{\mathrm{a}}$ is assumed for the load.

The gravity effects of the simple models of flexure are shown in Figure 5 in map form and in Figure 6 as profiles across the seamount. The computations have been carried out for effective flexural rigidities of the lithosphere of $2 \times 10^{29}, 6 \times 10^{29}$, and $4 \times 10^{30} \mathrm{dyn} \mathrm{cm}$. The computations show a largeamplitude positive gravity anomaly associated with the crest of the seamount that varies in amplitude from +231 to $282 \mathrm{mGal}$. The positive anomalies are bordered by a broad region of negative gravity anomalies in the range -11 to $-30 \mathrm{mGal}$. The gravity anomalies are slightly positive in the region bordering the negative anomalies.

The amplitude and the wavelength of the computed gravity anomalies change for different values of the assumed effective flexural rigidity of the lithosphere (maps B, C, and D in Figure 5; Figure 6). Large-amplitude positive anomalies (up to +282 mGal), small-amplitude negative anomalies (up to $-14 \mathrm{mGal}$ ), and long-wavelength anomalies characterize an effective flexural rigidity of $4 \times 10^{30} \mathrm{dyn} \mathrm{cm}$. Smaller-amplitude positive 
anomalies (up to $+231 \mathrm{mGal}$ ), larger-amplitude negative anomalies (up to $-30 \mathrm{mGal}$ ), and shorter-wavelength anomalies characterize an effective flexural rigidity of $2 \times 10^{29}$ dyn $\mathrm{cm}$. The differences between the gravity anomalies resulting from these effective flexural rigidities are clearly significant, and it should be possible to distinguish between them in observed free-air anomalies in the vicinity of the seamount.

An observed free-air anomaly map of the seamount is shown in map A of Figure 5. The map shows that the summit of the seamount correlates with positive anomalies of about $+250 \mathrm{mGal}$. Negative anomalies in bordering regions reach a minimum in the range -13 to $-43 \mathrm{mGal}$. The lowest values are observed north of the seamount and may arise at least partly from the additional load of the Hyeres seamount to the north. The regions east and south of the seamount are associated with negative anomalies of about $-13 \mathrm{mGal}$.

A comparison of the computed gravity anomalies with the observed free-air anomalies gives a likely range of values for the effective flexural rigidity of the lithosphere. The computed gravity anomalies for an effective flexural rigidity of $2 \times 10^{20}$ dyn $\mathrm{cm}$ (map $\mathrm{C}$ in Figure 5) predict smaller-amplitude positive anomalies associated with the crest of the seamount and larger-amplitude negative anomalies in peripheral regions. than are observed (map $A$ in Figure 5). Furthermore, the anomalies computed for an effective flexural rigidity of $4 \times 10^{30}$ dyn cm (map $B$ in Figure 5) predict largeramplitude positive anomalies associated with the crest of the seamount and smaller-amplitude negative anomalies in peripheral regions than are observed (map $A$ in Figure 5). Thus this comparison suggests that the effective flexural rigidity is between $2 \times 10^{20}$ and $4 \times 10^{30}$ dyn $\mathrm{cm}$.

Clearly, the ability to obtain a best-fitting effective flexural rigidity depends partially on the accuracy of the observed data and partially on successful isolation of the total gravity effect of the seamount from other contributions to the gravity field in the region. These contributions could take the form of longwavelength regional changes in gravity as well as shortwavelength local changes such as would be expected in regions of rugged sea floor topography. For an individual seamount, such as the Great Meteor seamount, the gravity anomalies associated with the flexure models in areas bordering the seamount are small and cannot easily be separated from the short-wavelength changes in gravity caused by rugged sea floor topography.

The general agreement between observed and computed

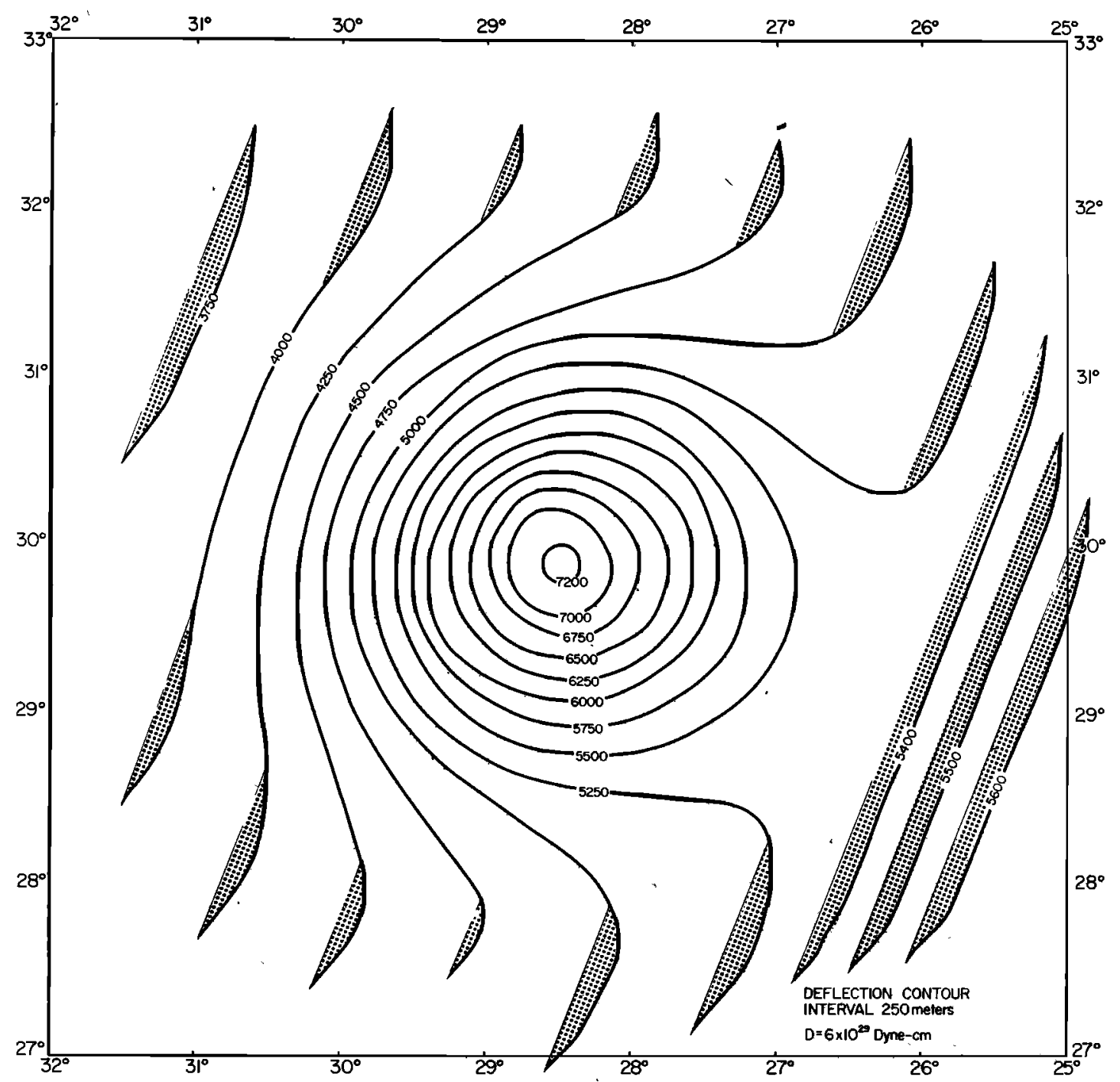

Fig. 4. Deflection of the lithosphere caused by the load of the Great Meteor seamount for an assumed flexural rigidity of the lithosphere, $D$, of $6 \times 10^{29}$ dyn $\mathrm{cm}$. The contoured surface shown represents the depth to the deformed surface of the upper crustal layer (layer 2). Regions of upward deflection are shaded. 

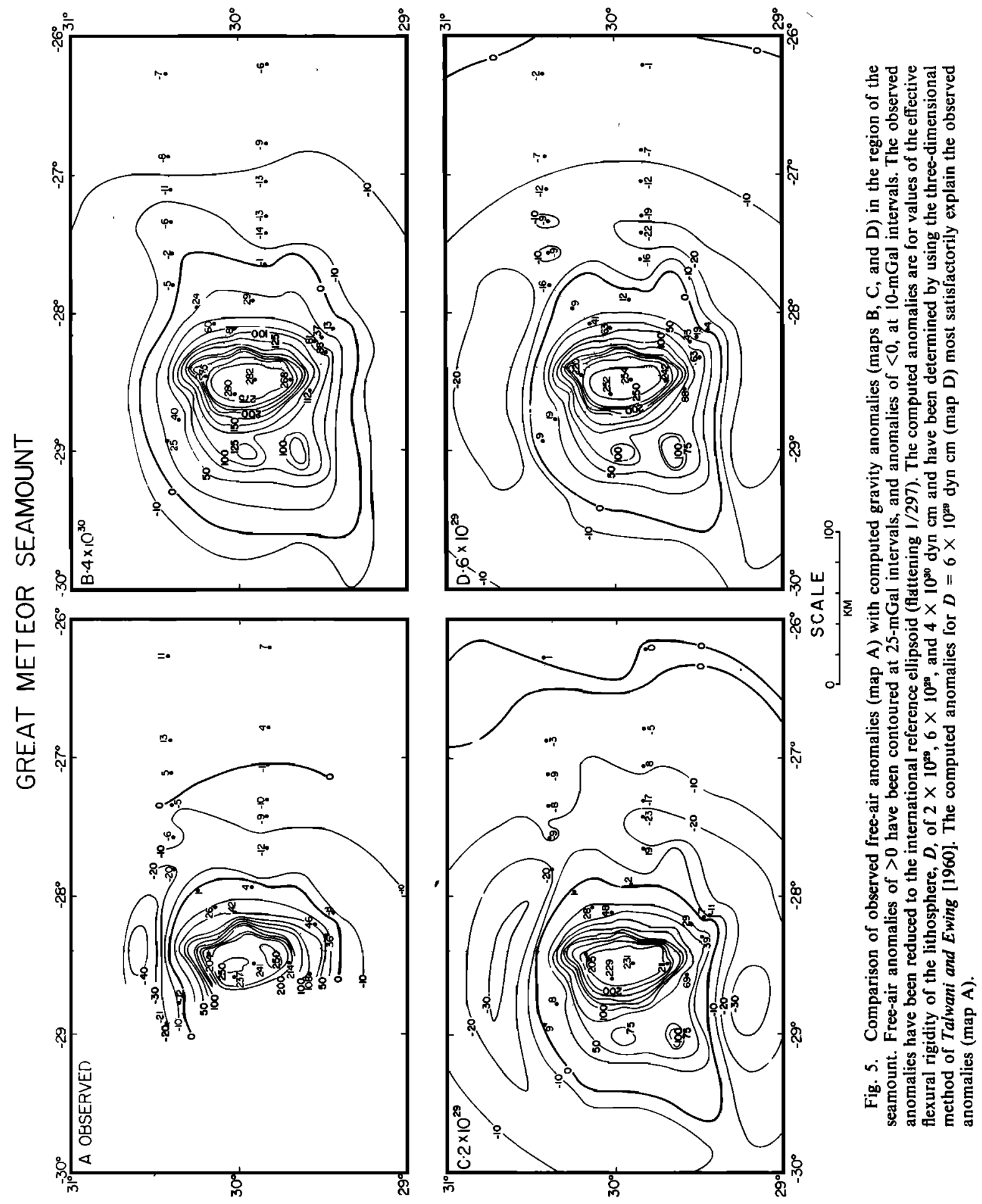


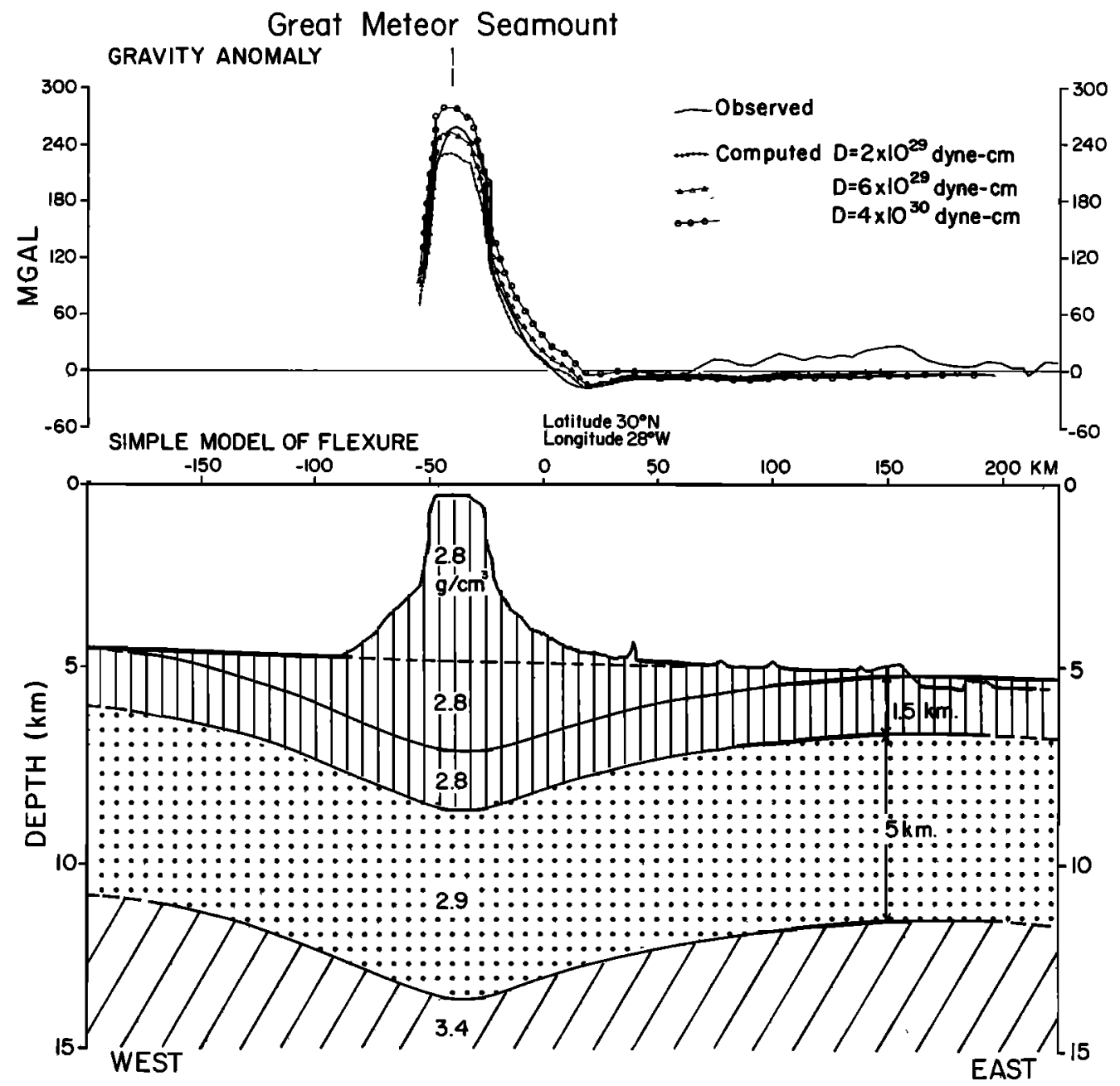

Fig. 6. Comparison of profiles of observed free-air anomalies with computed gravity anomalies in the region of the seamount. The computed profiles have been constructed from maps B, C, and D of Figure 5. The model of crustal deflection shown has been computed for an effective flexural rigidity of $6 \times 10^{29} \mathrm{dyn} \mathrm{cm}$.

gravity anomalies (Figures 5 and 6 ) allows, however, a bestfitting value for the effective flexural rigidity to be determined. We show in Figure 5 (map D) and Figure 6 the computed effect for an effective flexural rigidity of $6 \times 10^{29}$ dyn $\mathrm{cm}$. The computed anomalies for this value, which is intermediate between $2 \times 10^{29}$ and $4 \times 10^{20} \mathrm{dyn} \mathrm{cm}$, are similar to the observed anomalies. The fit is particularly good on the crest of the seamount (Figures 5 and 6). The mean discrepancy between observed and computed anomalies for this rigidity is $+2.0 \mathrm{mGal}$. We thus conclude from this comparison that the best-fitting value for the effective flexural rigidity of the lithosphere in the region of the Great Meteor seamount is about $6 \times 10^{29} \mathrm{dyn} \mathrm{cm}$.

\section{INTERPRETATION AND DISCUSSION}

There is good evidence that the effective flexural rigidity is closely related to the actual properties of the lithosphere. Thus the comparison of determinations of the effective flexural rigidity obtained from the study of loads of different ages can provide important information on the long-term behavior of the lithosphere. In addition, since the effective flexural rigidity is proportional to the cube of the effective thickness, determinations of the effective flexural rigidity in the vicinity of loads of similar ages may provide information on regional changes in the thickness of the lithosphere.

In Table 1 we have compared the best-fitting effective flex- ural rigidity obtained from the Great Meteor seamount with determinations obtained in other studies. Unfortunately, we cannot compare the Great Meteor value directly, since its age is poorly known. The location of the seamount near the 81m.y. isochron of Pitman and Talwani [1972] places an upper limit on the possible age. The foraminiferal limestones present on the summit of the seamount [Pratt, 1963] suggest an age greater than $7 \mathrm{~m}$.y. The comparison does show, however, that the effective flexural rigidity determined for the Great Meteor seamount is similar to values previously determined for the Hawaiian ridge and the Emperor seamounts, which are generally lower than values for the Caribou Mountains or the interior plains of Canada (Table 1).

We have recently concluded that the effective flexural rigidity does not change significantly with time for loads with a duration greater than a few million years [Watts and Cochran, 1974]. This conclusion was based on a study of the loads of the Emperor seamounts and the Hawaiian ridge, which range in age from about 3 to $60 \mathrm{~m} . \mathrm{y}$. and are located on the same relatively old (80-120 m.y.) oceanic lithospheric plate. The Great Meteor seamount is also located on relatively old (about 80 m.y.) oceanic lithosphere. Thus the similarity of the Great Meteor value to the Emperor seamounts. and Hawaiian ridge values is further support for this conclusion.

The difference between the Emperor seamount-Hawaiian ridge and Great Meteor values and the interior plains of 
TABLE 1. Comparison of Best-Fitting Effective Flexural Rigidity Obtained From the Great Meteor Seamount With Determinations From other Studies

\begin{tabular}{|c|c|c|c|c|}
\hline Lithosphere & Load & $\begin{array}{l}\text { Effective } \\
\text { Flexural } \\
\text { Rigidity } D, \\
\text { dyn cm }\end{array}$ & $\begin{array}{l}\text { Age of } \\
\text { Load } \\
\times 10^{6} \mathrm{yr}\end{array}$ & Reference \\
\hline Continent & $\begin{array}{l}\text { Caribou } \\
\text { Mountains }\end{array}$ & $3 \times 10^{30}$ & 5 & Waleott [1970a] \\
\hline Continent & $\begin{array}{l}\text { Interior } \\
\text { plains }\end{array}$ & $4 \times 10^{30}$ & 5 & Walcott $[1970 a]$ \\
\hline $\begin{array}{l}\text { Ocean } \\
\qquad(100-120 \mathrm{m.y.})\end{array}$ & $\begin{array}{l}\text { Hawaiian } \\
\text { ridge- } \\
\text { Emperor } \\
\text { seamounts }\end{array}$ & $5 \times 10^{29}$ & $3-60$ & $\begin{array}{l}\text { Watts and Cochran } \\
{[1974]}\end{array}$ \\
\hline $\begin{array}{l}\text { Ocean } \\
\quad\left(80 \mathrm{~m} . \mathrm{y}_{.}\right) \\
\text {Continent/ocean (?) }\end{array}$ & $\begin{array}{l}\text { Great } \\
\text { Meteor } \\
\text { Amazon cone }\end{array}$ & $\begin{array}{l}6 \times 10^{29} \\
2 \times 10^{30}\end{array}$ & $\begin{array}{l}7-80 \\
\text { uncertain }\end{array}$ & $\begin{array}{l}\text { This paper } \\
\text { Cochran [1973] }\end{array}$ \\
\hline
\end{tabular}

Canada and Caribou Mountains values could be caused, at least partly, by differences in thickness between these oceanic and continental lithospheric plates. The Great Meteor seamount, the Hawaiian ridge, and the Emperor seamounts are all located on oceanic lithosphere that was probably relatively old at the time of loading, whereas the Caribou Mountains and the interior plains of Canada are located on continental lithosphere. The ratio of the thickness of the oceanic lithosphere to that of the continental lithosphere, $T o / T c$, is given by

$$
T o / T c=(D o / D c)^{1 / 3}
$$

where $D .3$ is the effective flexural rigidity of the oceanic lithosphere and $D c$ is the effective flexural rigidity of the continental lithosphere. With $D o=6 \times 10^{29}$ and $D c=4.5 \times 10^{30}$ dyn $\mathrm{cm}$ (Table 1) we get $T o / T c \sim 2$. Thus a factor of about 2 difference between the actual thickness of the old oceanic lithosphere and that of the continental lithosphere could explain the observed differences.

Clearly, the implication of changes in the effective flexural rigidities is still uncertain owing in part to a limited number of determinations. We believe, however, that with the aid of a method of studying three-dimensional loads on the lithosphere a number of isolated seamounts can now be studied. We should then be able to obtain more effective flexural rigidity determinations and to understand better the long-term mechanical properties of the lithosphere as well as the regional changes in its thickness.

Acknowledgments. We thank U. Fleischer, M. Langseth, G. Sutton, and J. K. Weissel for critically reading the manuscript and for offering helpful suggestions. T. Aitken was chief scientist on the $R / V$ $V e m a$ cruise to the Great Meteor seamount. This research was funded by Office of Naval Research contract N00014-67-A-0108-0004 and National Scierce Foundation grant GA-27281. Lamont-Doherty Geological Observatory contribution 2202.

\section{REFERENCES}

Aric, K., H. Hirschleber, H. Menzel, and W. Weigel, Uber die Struktur der Gro en Meteor-Bank nach seismischen Ergebnissen, Meteor Forschungsergeb., Reihe $C$. no. 3, 49, 1970.

Barrell, J., The strength of the earth's crust, 8, Physical conditions controlling the nature of lithosphere and asthenosphere, J. Geol. 23, 425-443, 1915.

Cochran, J. R., Gravity and magnetic investigations in the Guinea basin, western equatorial Atlantic, Geol. Soc. Amer. Bull., 84, 3249-3268, 1973 .

Ewing, J., Seismic model of the Atlantic Ocean, in The Earth's Crust and Upper Mantle, Geophys. Monogr. Ser., vol. 13, edited by P. J. Hart, pp. 220-225, AGU, Washington, D. C., 1969.

Fleischer, U., O. Meyer, and $H$. Schaff, On the structure of the submarine tablemounts south of the Azores as derived from a gravimetric-magnetic north-south profile across the Grosse Meteor bank, Meteor Forschungsergeb., Reihe $C$, no. 3, 37-47, 1970.

Graf, A., and R. Schulze, Improvements on the sea gravimeter Gss2, J. Geophys. Res., 66, 1813-1821, 1961.

Gunn, R., A quantitative evaluation of the influence of the lithosphere on the anomalies of gravity, J. Franklin Inst., 236, 373-396, 1943.

Gunn, R., Quantitative aspects of juxtaposed ocean deeps, mountain chains and volcanic ranges, Geophysics, 12, 238-255, 1947.

Gunn, R., Isostasy extended, J. Geol., 57, 263-279, 1949.

Heezen, B. C., and C. D. Hollister, The Face of the Deep, Oxford University Press, New York, 1971.

Heezen, B. C., M. Ewing, and D. B. Ericson, Flat-topped Atlantis, Cruiser, and Great Meteor seamounts (abstract), Geol. Soc. Amer. Bull., 65, 1261, 1954.

Heiskanen, W. A., and F. A. Vening Meinesz, The Earth and Its Gravity Field. McGraw-Hill, New York, 1958.

Hertz, H., On the equilibrium of floating elastic plates, Wiedemann's Ann., 22, 449, 1884.

Hinz, K., The Great Meteor seamount, Results of seismic reflection measurements with pneumatic sound source and their geological interpretation, Meteor Forschungsergeb., Reihe C, no. 2, 63-77, 1969.

LaCoste, L. J. B., and J. C. Harrison, Some theoretical considerations in the measurement of gravity at sea, Geophys. J. Roy. Astron. Soc., 5(2), 89-103, 1961.

Pitman, W. C., III, and M. Talwani, Sea-floor spreading in the North Atlantic, Geol. Soc. Amer. Bull., 83, 619-646, 1972.

Pratt, R. M., Great Meteor seamount, Deep Sea Res., 10, 17-25, 1963.

Talwani, M., and M. Ewing, Rapid computation of gravitational attraction of three-dimensional bodies of arbitrary shape, Geophysics, 25(1), 203-225, 1960.

Uchupi, E., Bathymetric atlas of the Atlantic, Caribbean and Gulf of Mexico, Ref. 7l-72. Woods Hole Oceanogr. Inst., Woods Hole, Mass., 1971.

Vening Meinesz, F. A., Une nouvelle méthode pour la réduction isostatique régionale de l'intensité de la pésanteur, Bull. Geod., 29. 1931.

Vening Meinesz, F. A., Gravity over the Hawaiian Archipelago and over the Madeira area, Proc. Kon. Ned. Akad. Wetensch., 44 pp., 1941 .

Walcott, R. I., Flexural rigidity, thickness, and viscosity of the lithosphere, J. Geophys. Res., 75, 3941-3954, $1970 a$.

Walcott, R. I., Isostatic response to loading of the crust in Canada, Can. J. Earth Sci., 7, 716-727, 1970 .

Walcott, R. I., Flexure of the lithosphere at Hawaii, Tectonophysics, 9. 435-446, 1970c.

Walcott, R. I., Gravity, flexure and the growth of sedimentary basins at a continental edge, Geol. Soc. Amer. Bull., 83, 1845, 1972.

Watts, A. B., and J. R. Cochran, Gravity anomalies and flexure of the lithosphere along the Hawaiian-Emperor seamount chain, Geophys. J. Roy. Astron. Soc., 38, 119-141, 1974.

Watts, A. B., and M. Talwani, Gravity anomalies seaward of deep-sea trenches and their tectonic implications, Geophys. J. Roy. Astron. Soc., 36, 57-90, 1974.

(Received August 13, 1974; revised December 9, 1974; accepted December 23, 1974.) 